\title{
Mechanisms and dynamics of crystal growth, viscous flow, and self-diffusion in silica glass
}

\author{
Marcio Luis Ferreira Nascimento* and Edgar Dutra Zanotto ${ }^{\dagger}$ \\ Vitreous Materials Laboratory, Department of Materials Engineering, Federal University of São Carlos, \\ 13.565-905 São Carlos-SP, Brazil \\ (Received 9 August 2005; revised manuscript received 28 November 2005; published 30 January 2006)
}

\begin{abstract}
We analyzed extensive literature data on crystal growth rate and viscosity in the temperature range between 1.1 $T_{g}$ (glass transition temperature) and the melting point of silica, $T_{m}$. We selected data for one silica glass type, having similar impurity contents, and confirmed that the normal growth model describes quite well the experimental growth rate data in this wide undercooling range. We then calculated effective diffusion coefficients from crystal growth rates, $D_{u}$, and from viscosity, $D_{\eta}$ (through the Eyring equation), and compared these two independent diffusivities with directly measured self-diffusion coefficients of silicon and oxygen in the same silica glass for which viscosity was measured. Our results show that silicon (not oxygen) controls the diffusion dynamics involved in both crystal growth and viscous flow in undercooled silica. This study not only unveils the transport mechanism in this important glass-forming material, but also validates the use of (easily measured) viscosity to account for the unknown transport term of the crystal growth expression in a wide range of undercoolings.
\end{abstract}

DOI: 10.1103/PhysRevB.73.024209

PACS number(s): 61.43.Fs, 66.10.-x, 81.10.Aj, 66.20.+d

\section{INTRODUCTION}

On cooling most liquids from the equilibrium temperature, spontaneous crystallization frequently impairs glass formation. On the other hand, controlled crystallization of certain glasses may lead to unusual glass ceramics (pore-free, polycrystalline materials of nanometric and uniform grain size) having many and diverse interesting properties and applications. However, key questions regarding nucleation and crystal growth kinetics in undercooled liquids and glasses are still open. For instance, which ions or "molecular units" move collectively above and below the glass transition range, $T_{g}$, and control these important phenomena? Is the (often used) viscosity coefficient capable of describing molecular transport at the crystal/liquid interface?

Recent research on crystal growth and diffusion kinetics in diopside glass ${ }^{1}$ demonstrated that $(i)$ screw dislocationmediated growth is the operative mechanism in a wide range of undercoolings from the melting point, $T_{m}$, to $1.1 T_{g}$; (ii) at low undercoolings $\left(T>0.9 T_{m}\right)$, where the diffusion data of $\mathrm{Si}$ and $\mathrm{O}$ are available, the diffusion coefficients calculated from crystal growth kinetics and from viscosity agree with the direct measurements of $\mathrm{Si}$ and $\mathrm{O}$ mobility. Therefore, these two ions move together and control the transport mechanism involved in crystal growth and viscous flow. But diffusion data were not available to test what occurs at deep undercoolings $\left(T<0.7 T_{m}\right)$. Reference 1 constituted a significant step in the knowledge of transport processes controlling crystal growth in undercooled silicate liquids, which had been poorly documented. It not only unveiled the diffusion mechanism in undercooled liquid diopside, but also validated the use of viscosity to account for the kinetic term of the crystal growth expression from $T_{m}$ to $1.1 T_{g}$.

Since, in Ref. 1 diffusion data of $\mathrm{Si}$ and $\mathrm{O}$ were only available at a narrow temperature interval near the melting point of diopside, these important results should be generalized (or not) by additional studies with other glass-forming systems for which silicon and oxygen diffusivities are available in a wider range of undercoolings. In the present article we perform a detailed analysis of crystal growth kinetics, viscous flow, and self-diffusion of $\mathrm{Si}$ and $\mathrm{O}$ in another system, that is silica, in a wide range of undercoolings, from $T_{m}$ to $1.1 T_{g}$ (for crystal growth and viscosity), from $0.84 T_{m}$ to $0.95 T_{g}$ for $\mathrm{Si}$ self-diffusion, and from $1.02 T_{g}$ to $0.74 T_{g}$ for $\mathrm{O}$ self-diffusion to discover which of these ions move collectively and control these two important kinetic phenomena.

Silica $\left(\mathrm{SiO}_{2}\right)$ is an important mineral from the geological standpoint and is also the most important glass former. In addition, high-silica glasses, having $>99.9 \% \quad \mathrm{SiO}_{2}$, best known as quartz glass or vitreous silica, have many and diverse important commercial applications, such as laboratory glassware, telescopic mirrors, optical filters, and fibers. Silica glass producers generally divide the whole spectrum of commercial, transparent silica glasses into five types, depending on the production method, content and type of impurities, denominated types I, II, III, IV, and V. In a forthcoming review paper we describe in detail and revisit the crystal growth behavior of each one of these five families of silica glasses. ${ }^{2}$ A relevant outcome of Ref. 2 is that the crystal growth rates and viscosities of silica glasses are extremely dependent on the impurity level, much more than in multicomponent silicate glasses, corroborating earlier findings of other authors, e.g., Hetherington et al. ${ }^{3}$ Thus, for the present study, it was important to compare crystal growth, viscosity, and self-diffusion data for similar silicas. We thus made a careful analysis by choosing all diffusivity, viscosity, and crystal growth rates for type I silica glasses having a similar impurity content (Table I).

In brief, type I glasses are obtained by melting natural or synthetic quartz crystals in electrical furnaces. Such glasses contain impurities, such as alkali metals inherited from the initial raw material, and a very small amount of structural water $\left(\mathrm{OH}^{-}\right)$. Type II glasses are obtained by melting grains of natural or synthetic quartz in hydrogen-oxygen gas flames. 
TABLE I. Impurity contents of type-I silica glasses used in this paper.

\begin{tabular}{|c|c|c|c|}
\hline Silica glass & Tracer elements (ppm) & $\mathrm{OH}^{-}(\mathrm{ppm})$ & Comments \\
\hline Puropsil A ${ }^{\circledR}$ & $\begin{array}{c}\mathrm{Al}(25), \mathrm{Ca}(1.0), \mathrm{Fe}(0.5), \\
\mathrm{Li}(1.0), \mathrm{Na}(0.5), \mathrm{Ti}(0.8), \\
\mathrm{K}(0.5): \\
\text { Puropsil } \mathrm{B}^{\circledR} \text { impurities } \\
\text { Total } \approx 29\end{array}$ & $\approx 8$ & $\begin{array}{l}\text { Puropsil } \mathrm{A}^{\circledR} \text { is no longer } \\
\text { produced, but it is similar } \\
\text { to Puropsil } \mathrm{B}^{\circledR} \text { (Ref. 20) }\end{array}$ \\
\hline GE $124^{\circledR}$ & $\begin{array}{c}\mathrm{Al}(20.3), \mathrm{Ca}(1.8), \\
\mathrm{Fe}(1.9), \mathrm{Li}(1.0), \mathrm{Mg}(0.5), \\
\mathrm{Mn}(0.1), \mathrm{Na}(1.3), \\
\mathrm{Ti}(1.4), \mathrm{Zr}(2.4) \\
\text { Total } \approx 31\end{array}$ & 33 & $\begin{array}{l}\text { Glass used by Kalen et al. } \\
\text { (Ref. 16) }\end{array}$ \\
\hline $\begin{array}{l}\text { Heraeus } \\
\text { Quarzglas }\end{array}$ & $\begin{array}{c}\mathrm{Al}(20), \mathrm{Ca}(1.0), \mathrm{Fe}(0.8), \\
\mathrm{Li}(1.0), \mathrm{Mg}(0.1), \\
\mathrm{Na}(1.0), \mathrm{Ti}(1.0), \mathrm{Cr}(0.1), \\
\mathrm{Cu}(0.1), \mathrm{K}(0.8): \\
\text { Infrasil }{ }^{\circledR} \text { impurities } \\
\text { Total } \approx 26^{2}\end{array}$ & $\approx 10$ & $\begin{array}{l}\text { The glass used by Haul and } \\
\text { Dümbgen (Ref. 15) was type } \\
\text { I. The commercial brand } \\
\text { name is unknown, but its } \\
\text { composition is probably } \\
\text { similar to that of modern } \\
\text { Infrasil }{ }^{\circledR} \text { (Ref. 21) }\end{array}$ \\
\hline $\begin{array}{l}\text { Wagstaff's } \\
\text { glass }\end{array}$ & $\begin{array}{c}\mathrm{Al}(137), \mathrm{Ca}(8), \mathrm{Fe}(5), \\
\mathrm{Li}(0.7), \mathrm{Mg}(4), \mathrm{Na}(27), \\
\mathrm{Ti}(3), \mathrm{K}(2) \\
\text { Total } \approx 187\end{array}$ & $\begin{array}{l}\text { Estimated } \\
\approx 10-30 \\
\quad \mathrm{ppm}\end{array}$ & $\begin{array}{c}\text { Type I silica glass should } \\
\text { contain only a few ppm } \\
\text { of } \mathrm{OH}^{-} \text {, similar to GE } \\
124^{\circledR} \text { glass }\end{array}$ \\
\hline
\end{tabular}

These glasses contain impurities inherited from mineral quartz (a similar content as in type I glasses) and several hundred ppm $\mathrm{OH}^{-}$. Type III glasses are obtained by the hightemperature hydrolysis of volatile compounds of silicon and are characterized by very low content of metal impurities, but contain a considerable concentration of structural water and chlorine. Type IV glasses are obtained by the hightemperature oxidation of $\mathrm{SiCl}_{4}$ and contain a very small amount of metal impurities, virtually no structural water, but several hundred ppm of chlorine. Type $\mathrm{V}$ silica is a synthetic material that involves sintering of a sol-gel-derived powder into a glass. This silica glass typically has contamination levels of about $0.1 \mathrm{ppm} \mathrm{OH}^{-}$and $400 \mathrm{ppm} \mathrm{Cl}^{-}$. Thin film silicas, on the other hand, have not yet been classified, but their properties depend on the level of impurities and on the specific technique used for their synthesis.

Several authors have determined crystal growth rates and viscosity at several undercoolings of several silica glasses having different impurity contents, ${ }^{2}$ but none of these previous studies analyzed crystal growth kinetics in a wide range of temperatures, from $T_{m}$ to $1.1 T_{g}$. To the best of our knowledge, crystallization rates and melting of cristobaliteincluding the region of maximum growth rate-were only obtained by Wagstaff., ${ }^{4,5}$ Also, there are no new crystal growth data for type-I silica in such a wide range of temperatures. Another reason that led us to choose Wagstaff's data was because, coincidently, among all the available data for silica glass type I, his glass presents the smallest crystal growth rates. Therefore it must have the least impurity content. Fortunately, Wagstaff's data cover the widest temperature range among all the available growth rate data for silica glasses. Hence, in a consistent way, in our analysis we combine the lowest crystal growth rates with the highest viscosity.
Despite its kinetic sensitivity to impurities, silica glass is an adequate model system for the type of study proposed here because it displays polymorphic crystallization, there is plenty of viscosity, crystal growth rate, and thermodynamic data, such as the melting point and Gibbs free energy of crystallization $(\Delta G)$, which substantially helps with the analysis. A final and most important motivating factor is that (hard to measure) self-diffusion coefficients of oxygen $\left(D_{\mathrm{O}}\right)$ and particularly silicon $\left(D_{\mathrm{Si}}\right)$, the slowest diffusing species in silicate glasses, are also available in wide temperature intervals.

In this paper we use the same strategy proposed and tested in Ref. 1 for diopside to infer which ion(s) control the crystal growth kinetics and viscous flow in undercooled liquid silica. We compare the effective diffusion coefficients determined in three distinct ways, i.e., calculated from crystal growth rates, $D_{u}$, estimated through viscosity data, $D_{\eta}$ (via the Eyring relation), and directly measured self-diffusion coefficients of silicon and oxygen.

To the best of our knowledge, this is the first time the transport mechanism that controls crystal growth kinetics and viscous flow in undercooled liquid silica are analyzed in detail in a wide temperature $\left(380{ }^{\circ} \mathrm{C}\right)$ and diffusivity range, covering eight orders of magnitude using independent, reliable experimental data on the thermodynamic driving force, viscosity, crystal growth rates, and diffusion coefficients. As the diffusion mechanisms involved in crystal nucleation and growth are unknown for most glasses, we go deeper into this question, by relating crystal growth kinetics with both viscous flow and directly measured diffusion data.

\section{ANALYSIS OF CRYSTAL GROWTH KINETICS}

Three phenomenological models are normally employed to describe interface controlled crystal growth processes in 
inorganic glasses: normal growth, screw dislocation growth, and two-dimensional (2-D) surface nucleated growth. According to Jackson's treatment of the interface, materials with low melting entropy $\left(\Delta S_{m}<2 R\right.$, where $R$ is the gas constant), such as silica $\left(\Delta S_{m} \cong 0.46 R\right)$, are expected to exhibit crystal growth kinetics of the form predicted by the normal growth model. ${ }^{6,7}$ Thus, in principle, the low melting entropy of silica $\left(\Delta S_{m}<4 R\right)$ excludes the screw dislocation and the 2-D surface nucleated growth models. However, to be on the safe side, we first tested all these growth models.

According to the normal growth model, the surface is atomically rough and the degree of roughness is independent on the temperature. The corresponding temperaturedependent growth rate $u$ may be expressed by ${ }^{6,7}$

$$
u=f \frac{D_{u}}{\lambda}\left[1-\exp \left(-\frac{\Delta G}{R T}\right)\right],
$$

where $D_{u}$ is an effective diffusion coefficient $\left(\mathrm{m}^{2} / \mathrm{s}\right)$ of the (unknown) molecular species that control atomic or molecular attachment at the liquid/crystal interface; $\lambda$ is the (unknown) diameter of the diffusing building molecules (m), which is equivalent to the jump distance, the crystal lattice parameter, or the unit distance advanced by the interface; $\Delta G$ is the free energy change upon crystallization $(\mathrm{J} / \mathrm{mol}) ; R$ is the gas constant $(\mathrm{J} / \mathrm{mol} \mathrm{K}) ; T$ is the absolute temperature $(\mathrm{K})$; and $f \cong 1$ is the fraction of preferred growth sites at the interface. In general, one uses $\Delta G$ calculated by the Turnbull's $\left(\Delta G=\Delta H_{m} \Delta T / T_{m}\right)$ or Hoffman's $\left(\Delta G=\Delta H_{m} \Delta T T / T_{m}{ }^{2}\right)$ approximations $\left(\Delta T=T_{m}-T\right.$ is the undercooling). ${ }^{6,7}$ The melting enthalpy $\Delta H_{m}$ of silica is approximately $7.679 \mathrm{~kJ} / \mathrm{mol}^{4,5}$

In the screw dislocation model, the surface is considered smooth, albeit imperfect on an atomic scale, and growth takes place at step sites provided by screw dislocations, considering $f \cong \Delta T / 2 \pi T_{m}$ [see Eq. (1)].

The remaining mechanism, the 2-D surface nucleated growth model considers the surface atomically smooth and defect-free. In this model, growth occurs by the formation of two-dimensional nuclei on the top of primary crystals, which grow laterally. ${ }^{6,7}$ The surface nucleation model is given by Eqs. (2a)-(2c):

$$
\begin{gathered}
u=C \frac{D_{u}}{\lambda^{2}} \exp \left(-\frac{B}{T \Delta G}\right), \\
B=\frac{\pi \lambda V_{m} \sigma^{2}}{3 k_{B}}, \\
C=\frac{\sqrt[3]{\pi N_{s} \lambda^{5} / 3}}{\Gamma(4 / 3)}\left[1-\exp \left(-\frac{\Delta G}{R T}\right)\right],
\end{gathered}
$$

where $V_{m}$ is the molar volume $\left(\mathrm{m}^{3} / \mathrm{mol}\right), k_{B}$ is the Boltzmann constant, $\sigma$ is the surface energy $\left(\mathrm{J} / \mathrm{m}^{2}\right), N_{s}$ is the number of growth sites per unit area $\left(\mathrm{m}^{-2}\right)$, and $\Gamma$ is the gamma function.

Crystallization is an exothermic process and knowledge of the crystal/liquid interface temperature is essential for analyzing crystal growth kinetics. Based on direct measurements for several glasses, Herron and Bergeron ${ }^{8}$ suggested and suc- cessfully tested empirical equations to estimate the liquidcrystal interface temperature for temperatures near the maximum crystal growth rate $\left(u_{\max }\right)$ and relatively far from it $\left(u<0.67 u_{\max }\right)$. Such expressions for interface temperature corrections are presented in Table II. For silica, these temperature corrections are only about $0.1^{\circ} \mathrm{C}$ for the maximum growth rate, because of the low growth rates and melting enthalpy. This correction was thus irrelevant for this particular glass.

The effective diffusivity can be estimated via the Eyring expression, Eq. (3), assuming that the molecular motion required for interfacial rearrangements controlling crystal growth is similar to that controlling viscous flow in the bulk liquid, $D_{\eta}$ :

$$
D_{\eta}=\frac{k_{B} T}{\lambda \eta},
$$

where $\eta$ is the shear viscosity, $\lambda$ is the jump distance or the (unknown) diameter of the (unknown) diffusing molecules, which has the order of a few angstroms. The Eyring (E) and Stokes-Einstein (SE) equations differ only by a factor of $3 \pi$. The SE expression describes a moving solid sphere with radius $R$ in a viscous liquid. Thus, for silicate glasses most authors prefer the Eyring equation because the meaning of the parameter $\lambda$, the jump distance, is most appropriate. However, the overall conclusions of this paper would not be altered if we employed the SE equation.

A recent study ${ }^{9,10}$ demonstrates that below the glass transition temperature, $T_{g}$, atomic motion through a metallic glass involves single-atom hopping, whereas motion above $T_{g}$ is more collective. Other authors ${ }^{11}$ previously observed such a substantial change in the diffusion mechanism for organic and Lennard-Jones liquids, but occurring at higher temperatures, i.e., at about $1.2-1.3 T_{g}$, and this temperature has been denominated decoupling temperature, $T_{d}$. A similar change in the diffusion mechanism at some $T_{d}>T_{g}$ is also suggested to occur for undercooled oxide liquids, but has not been firmly proved yet. It has thus been a matter of discussion if the Stokes-Einstein and Eyring equations can be used for calculations of crystal growth kinetics at deep undercoolings, below $T_{d} \approx 1.2 T_{g}$, where it has been suggested that these equations fail. ${ }^{11,12}$ However, these equations are considered to be valid at temperatures greater than $T_{d}$, which includes the range of interest in this paper.

From the previous discussion, to test the governing mechanism of crystal growth, one must know the glass viscosity, $\eta(T)$ the free energy change due to crystallization, $\Delta G(T)$, and the crystal growth rates, $u(T)$. Once the crystal growth mechanism is confirmed, one can calculate and compare two distinct diffusion coefficients, obtained from crystal growth rates, and viscosity with directly measured selfdiffusion coefficients.

\section{RESULTS AND DISCUSSION}

\section{A. Growth mechanism and the jump distance}

A large collection of viscosity and crystal growth rates from different authors, using several silica type-I glasses, 
TABLE II. Physical parameters and equations used in this paper.

\begin{tabular}{|c|c|c|}
\hline $\begin{array}{l}\text { Glass transition } \\
\text { temperature }\end{array}$ & $T_{g}(\mathrm{~K})$ & $\begin{array}{l}1451 \text { (estimated from the viscosity curve of } \\
\text { Puropsil } A^{\circledR} \text { glass; Ref. 13) }\end{array}$ \\
\hline Melting temperature & $T_{m}(\mathrm{~K})$ & $\begin{array}{c}\approx 2007 \text { (experimental temperature where } \\
\text { cristobalite } \\
\text { crystals dissolve) (Refs. } 4 \text { and } 5)\end{array}$ \\
\hline Viscosity & $\eta(\mathrm{Pa} \mathrm{s}), T(\mathrm{~K})$ & $\begin{array}{c}\log \eta=-8.81+30193.77 / T\left(0.83 T_{m}<T<0.95 T_{g}\right) \\
\text { (Puropsil A }{ }^{\circledR} \text { glass; Ref. 13) }\end{array}$ \\
\hline $\begin{array}{l}\text { Molar enthalpy of } \\
\text { melting }\end{array}$ & $\Delta H_{m}(\mathrm{~kJ} / \mathrm{mol})$ & 7.679 \\
\hline Molar volume & $V_{m}\left(\mathrm{~m}^{3} / \mathrm{mol}\right)$ & $2.72 \times 10^{-5}$ \\
\hline $\begin{array}{l}\text { Maximum } \\
\text { experimental } \\
\text { growth rate }\end{array}$ & $u_{\max }(\mathrm{m} / \mathrm{s})$ & $2 \times 10^{-9}$ \\
\hline Temperature of $u_{\max }$ & $T_{\max }(\mathrm{K})$ & 1950 \\
\hline $\begin{array}{l}\text { Diffusivity from } \\
\text { crystal growth rates }\end{array}$ & $\begin{array}{c}D_{u}\left(\mathrm{~m}^{2} / \mathrm{s}\right), T \\
(\mathrm{~K})\end{array}$ & $\begin{array}{c}\log D_{u}=-1.85-28553.56 / T ; E\left(D_{u}\right)=5.7 \pm 0.2 \mathrm{eV} \\
\left(T_{m}<T<1.1 T_{g}\right)\end{array}$ \\
\hline $\begin{array}{l}\text { Diffusivity from } \\
\text { viscosity }\end{array}$ & $\begin{array}{l}D_{\eta}\left(\mathrm{m}^{2} / \mathrm{s}\right), T \\
(\mathrm{~K})\end{array}$ & $\begin{array}{c}\log D_{\eta}=-0.693-30908.96 / T ; E\left(D_{\eta}\right)=6.1 \pm 0.1 \mathrm{eV} \\
\left(0.83 T_{m}<T<0.95 T_{g}\right)\end{array}$ \\
\hline Silicon diffusivity (Ref. 13) & $\begin{array}{l}D_{\mathrm{Si}}\left(\mathrm{m}^{2} / \mathrm{s}\right), T \\
(\mathrm{~K})\end{array}$ & $\begin{array}{c}\log D_{\mathrm{Si}}=-1.25-30609.24 / T ; E\left(D_{\mathrm{Si}}\right)=6.1 \pm 0.2 \mathrm{eV} \\
\left(0.84 T_{m}<T<0.95 T_{g}\right)\end{array}$ \\
\hline $\begin{array}{l}\text { Oxygen diffusivity } \\
\text { (Haul and } \\
\text { Dümbgen, Ref. 15) }\end{array}$ & $\begin{array}{l}D_{\mathrm{O}}\left(\mathrm{m}^{2} / \mathrm{s}\right), T \\
(\mathrm{~K})\end{array}$ & $\begin{array}{c}\log D_{\mathrm{O}}=-7.969-14308.5 / T ; E\left(D_{\mathrm{O}}\right)=1.1 \pm 0.2 \mathrm{eV} \\
\left(1.01 T_{g}<T<0.81 T_{g}\right)\end{array}$ \\
\hline $\begin{array}{l}\text { Oxygen diffusivity } \\
\text { (Kalen et al., Ref. 16) }\end{array}$ & $\begin{array}{c}D_{\mathrm{O}}\left(\mathrm{m}^{2} / \mathrm{s}\right), T \\
(\mathrm{~K})\end{array}$ & $\begin{array}{c}\log D_{\mathrm{O}}=-15.71-5432.54 / T ; E\left(D_{\mathrm{O}}\right)=2.9 \pm 0.2 \mathrm{eV} \\
\left(1.02 T_{g}<T<0.74 T_{g}\right)\end{array}$ \\
\hline $\begin{array}{l}\text { Correction of } \\
\text { interface temperature }\end{array}$ & $\begin{array}{c}\Delta T_{i}(\mathrm{~K}) \\
u(\mathrm{~cm} / \mathrm{s}) \text { and } \\
\Delta H_{m}(\mathrm{cal} / \mathrm{mol})\end{array}$ & $\begin{array}{c}\Delta T_{i}=9.67\left(u \Delta H_{m}\right)^{0.556} \text { for } u<0.67 u_{\max } \\
\Delta T_{i}=17.12\left(u_{\max } \Delta H_{m}\right)^{0.486} \text { near } u_{\max }\end{array}$ \\
\hline
\end{tabular}

with distinct impurity contents, were analyzed elsewhere., ${ }^{2,3}$ Arrhenius plots describe all these viscosity data in wide temperature ranges. Most viscosity curves for the purest type-I silica glasses are similar to that of Puropsil A glass, ${ }^{13}$ and the resulting equation is listed in Table II. This equation was thus used throughout this paper.

Figure 1 shows the crystal growth rate data of Wagstaff for a type-I silica glass. ${ }^{4,5}$ His data span about two orders of magnitude in a wide range of undercoolings, from $1.1 T_{g}$ to $T_{m}$. As shown in Ref. 2, there is a large scatter of the crystal growth rates and viscosity for silica glasses, indicating that, especially for this glass, $u$ and $\eta$ are very sensitive to the fabrication method and impurity content. This is because pure silica has a fully polymerized network $\left(Q^{4}\right.$ in NMR notation), and the addition of impurities breaks down the network producing a distribution of $Q^{n}(n=1,2,3,4)$ types that strongly affects transport phenomena such as those focused here. Please consult Ref. 2 for more details. That is why we combined the lowest crystal growth rates from Refs. 4 and 5 with the highest viscosity data from Ref. 13.

For stoichiometric (polymorphic) crystallization, as in the present case, short-range molecular diffusion through the crystal/melt interface is expected to govern crystal growth. However, in most theoretical analyses of crystal growth kinetics in undercooled liquids, it is assumed that this type of molecular transport is determined by an effective diffusion coefficient in the liquid, which is related to viscosity by the Eyring equation [Eq. (3)]. With this assumption, to analyze growth rate data one can thus insert Eq. (3) in Eq. (1), assuming $D_{u}=D_{\eta}$, and use the independent experimental values of $\eta(T)$ and $\Delta G(T)$ calculated by the Turnbull equation. However, the true size (and nature) of the diffusing atoms or "building molecules" in Eqs. (1) and (3), $\lambda$, remains unknown. One can thus leave $\lambda$ as an adjustable parameter and fit Eq. (1) to the growth rate data.

Figure 1 shows a fitted growth rate curve, using the normal growth equation [Eq. (1) with $f=1$ ] and $D_{\eta}$ from the Eyring equation, which resulted in $\lambda=1.99 \AA$ (a solid line). This fitted value of $\lambda$ has the expected magnitude and is not far from the Si-O distance (1.59 $\AA$ ) measured by several authors in silica glass; see, for instance, Ref. 14. As a matter of fact, we considered the jump distance of Eq. (1) equal to the diameter of the flow unities in Eq. (3). This is a fair approximation because both are unknown, but one expects that the values of jump distance and flow unity size have similar magnitudes, and facilitates the calculations performed in Figs. 1 and 2.

Figure 1 also shows the curves calculated for the screw dislocation and 2-D surface nucleation growth models. To best fit the growth rate data, assuming the screw dislocation mechanism, the diameter of the diffusing building molecules, $\lambda$, should be $0.008 \AA$ if one uses the diffusivity given by the 


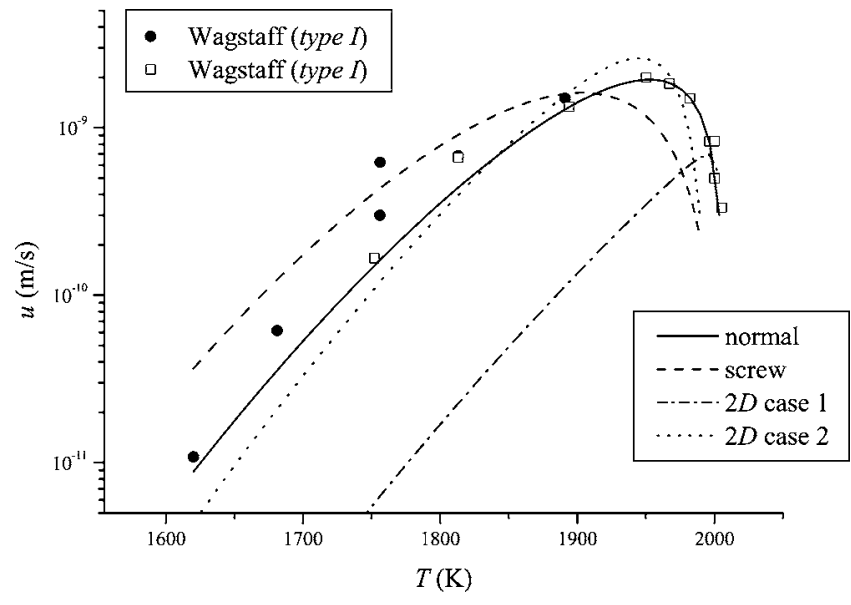

FIG. 1. The solid line is a fitted curve using the normal growth model with $D_{\eta}$ calculated by the Eyring equation and $\Delta G$ given by the Turnbull expression. Using the crystal growth data of Wagstaff (Refs. 4 and 15) and viscosity for Puropsil $\mathrm{A}^{\circledR}$ glass (Ref. 13) the fitted jump distance was $1.99 \AA\left(R^{2}=0.96\right)$. The dashed line shows the calculated $u(T)$, considering the screw dislocation growth. The dashed-dotted and dotted lines correspond to the surface nucleated growth, considering $C$ as a constant [Eq. (2c)], $\lambda=1 \AA$ and $\sigma$ as $9.0 \mathrm{~mJ} / \mathrm{m}^{2}$ (2-D case 1$)$ and $53 \mathrm{~mJ} / \mathrm{m}^{2}$ (2-D case 2$)$, respectively.

Eyring expression (please refer to Eq. (3) and explanations therein). This value of $\lambda$ is, however, about two orders of magnitude smaller than expected, and the fitted curve (the dashed line in Fig. 1) does not adjust well to the experimental data. The 2-D nucleation growth model was also discarded because Eq. (2a) could not fit all the experimental growth rate data [even considering the best possible conditions: a jump distance of $1 \AA$, surface energy $\sigma$ $=150 \mathrm{~mJ} / \mathrm{m}^{2}$, and $N_{s}=1.89 \times 10^{22} \mathrm{~m}^{-2}$ (not shown in Fig. 1)]. Better theoretical results, but still far from the experimental crystal growth curve, were obtained, considering $C$ as a constant in Eq. (2c), the same jumping distance of $1 \AA$, and surface energies $\sigma=9.0 \mathrm{~mJ} / \mathrm{m}^{2}$ (2-D case 1, dashed-dotted line) and $53 \mathrm{~mJ} / \mathrm{m}^{2}$ (2-D case 2, dotted line), respectively. These values of $\sigma$ were taken from a $\ln u \eta / T$ vs $1 / T \Delta G$ plot, which show two different slopes. Wagstaff ${ }^{5}$ also discarded the screw dislocation and 2-D models in his analysis of growth rates at low undercoolings. Thus, for undercooled liquid silica, the normal growth model is by far the best.

\section{B. Diffusion coefficients}

Since we now know the governing growth mechanism, let us then analyze the diffusion coefficients in more detail. For normal growth one can isolate an effective diffusion coefficient, $D_{u}$, from Eq. (1), as shown by Eq. (4),

$$
D_{u}=u \lambda\left[1-\exp \left(-\frac{\Delta G}{R T}\right)\right]^{-1} \text {. }
$$

This parameter can be estimated using the experimental growth rate data and $\lambda=1.99 \AA$ from the previous fit (or the Si-O distance $\lambda=1.59 \AA$ ). Our aim is to compare the effective diffusion coefficients $D_{u}$, calculated from crystal growth

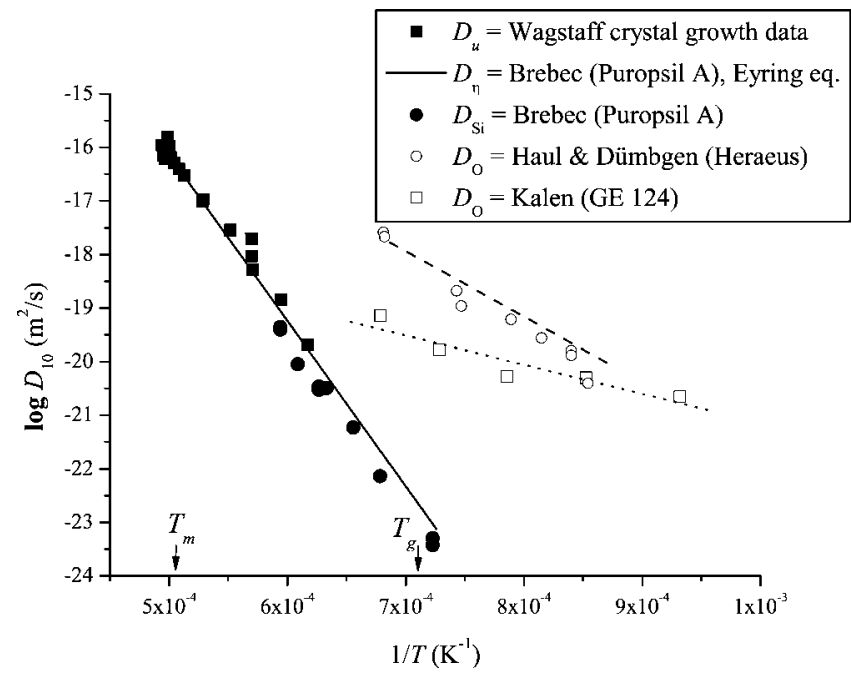

FIG. 2. Logarithm of four different effective diffusion coefficients in type-I silica glasses: $D_{u}$ : calculated from crystal growth rate data (Refs. 4 and 5) [Eq. (4)] between $1.1 T_{g}<T<T_{m}$ (black squares); $D_{\eta}$ : solid line=diffusion coefficient calculated by the Eyring equation [Eq. (3)] using viscosity data of Puropsil $\mathrm{A}^{\circledR}$ (Ref. 13) with $\lambda=1.99 \AA$ from a fit to experimental $u(T)$ (Refs. 4 and 5); $D_{\mathrm{Si}}$ and $D_{\mathrm{O}}$ : measured self-diffusion coefficients (Refs. 13, 16, and 17) of $\mathrm{Si}^{4+}$ and $\mathrm{O}^{2-}$ (see the respective symbols and commercial brand names in the insert). Dashed and dotted lines through the oxygen diffusion coefficients are Arrhenius fits to the experimental data.

kinetics, with $D_{\eta}$, calculated via viscosity by the Eyring expression [Eq. (3)]. Figure 2 shows good agreement between $D_{u}$ and $D_{\eta}$; most values are within a half-order of magnitude, and, most importantly, the calculated line $\left(D_{\eta}\right)$ correctly describes the temperature dependence of the effective diffusion coefficient for crystal growth. This congruence indicates that, whatever the bond breaking and molecular reorientation mechanism required for crystallization is, it is the same as that required for the atomic transport mechanism that controls viscous flow.

Figure 2 also shows experimental values of silicon $\left(\mathrm{Si}^{4+}\right)$ and oxygen $\left(\mathrm{O}^{2-}\right)$ diffusivities of type-I silica glasses in undercooled liquid silica ${ }^{13,15,16}$ between $800{ }^{\circ} \mathrm{C}$ and $1400{ }^{\circ} \mathrm{C}$. These diffusivities differ by many orders of magnitude. $D_{\mathrm{O}}$ does not agree with the calculated $D_{u}$ and $D_{\eta}$, but the $D_{\mathrm{Si}}$ does. This finding confirms that viscous flow and crystal growth in undercooled silica are controlled by silicon diffusion.

An ideal test would be one with the four types of diffusivities determined for the same glass in the same temperature range, but unfortunately such data are not available. We were thus careful to choose data for glasses of the same family (type I) having similar impurity contents (Table I). The glass used for crystal growth rate measurements (Wagstaff's glass) had a somewhat higher impurity level than those used for measurements of viscosity and silicon selfdiffusion (Puropsil A), and oxygen self-diffusion (GE and Heraus glasses). However, the values of $D_{u}, D_{\eta}$, and $D_{\mathrm{Si}}$ are coherent.

For some multicomponent silicate glasses, it has been shown that oxygen is one of the rate-determining species for 
viscous flow (e.g., see Schaeffer ${ }^{17}$ ). Recently, we confirmed such behavior in a study of viscous flow, crystal growth, and self-diffusion kinetics in a diopside at low undercoolings. ${ }^{1}$ There is no self-diffusion data at high undercoolings $\left(\approx T_{g}\right)$ for diopside, but silicon and oxygen move at the same rate at low undercoolings. For the present silica glasses, a good reason to compare the oxygen diffusivities obtained by Kalen $e t$ $a l .{ }^{16}$ and Haul and Dümbgen ${ }^{15}$ with $D_{u}, D_{\eta}$, and $D_{\mathrm{Si}}$ is the fact that all these data are for type-I silicas with similar impurity contents (Table I). Schaeffer ${ }^{17}$ had already demonstrated that the activation energy for oxygen self-diffusion in undercooled silica is about $1.0 \mathrm{eV}$, much less than the singlebond strength between silicon and oxygen $(4.8 \mathrm{eV})$.

It is quite difficult to determine very sluggish diffusion coefficients such as those of Fig. 2, but Brebec et al. ${ }^{13}$ managed to measure $\mathrm{Si}^{4+}$ diffusion in a type I silica glass (Puropsil A) using Secondary Ion Mass Spectroscopy. The measured activation energy for $\mathrm{Si}^{4+}$ diffusion, $D_{\mathrm{Si}}$, was $6.1 \mathrm{eV}$ in the temperature range between $1140{ }^{\circ} \mathrm{C}$ and $1410{ }^{\circ} \mathrm{C}$. The magnitude of the calculated diffusivity for viscous flow and its respective activation energy do not agree with the activation energy and diffusivity of oxygen, but agree quite well with $D_{\mathrm{Si}}$ and respective activation energy.

It should be emphasized, however, that oxygen diffusion data for type-I $\mathrm{SiO}_{2}$ glasses, shown in Fig. 2, reveal a larger scatter of activation energies and preexponential factors. The most important causes for such variation are experimental limitations of the techniques employed in each work. On the other hand, it is absolutely clear from Fig. 2 that, despite this large scatter, the oxygen diffusion coefficients are several orders of magnitude higher, and that their temperature dependences (activation energies 1.1-2.8 eV) are less than half those of silicon. We did not consider the oxygen diffusion measurements of Mikkelsen ${ }^{18}$ because he used a thin film and did not mention its impurity content. In that paper, the author compared the measured diffusivities with those determined by Haul and Dümbgen, ${ }^{15}$ and found them to be 10 to 100 times lower (with activation energy of $4.7 \mathrm{eV}$ in the temperature range $1200{ }^{\circ} \mathrm{C}$ to $1400{ }^{\circ} \mathrm{C}$ ). Obviously, the effect of impurities should have been considered in that analysis.

Therefore, the agreement of the activation energies and diffusion coefficients calculated from viscosity and from crystal growth rates with directly measured self-diffusion of silicon (but not of oxygen, see Table II) suggests that $\mathrm{Si}$ and $\mathrm{O}$ do not obey similar diffusion mechanisms, and thus do not diffuse together during crystal growth in silica. But, since silicon and bridging oxygen $(\mathrm{BO}=\mathrm{Si}-\mathrm{O}-\mathrm{Si})$ are tightly linked, one might reasonably argue why the diffusivities of these two network building species are so different? A reasonable explanation is that when one measures oxygen diffusivity in silica, in reality only the movement of nonbridging oxygen $\mathrm{NBO}=\mathrm{Si}-\mathrm{O}-\mathrm{M}$, where $\mathrm{M}$ refers to impurity elements in the glass), which are not so tightly bound to the silicon tetrahedra, dominate, and are detected because they move much faster than $\mathrm{BO}$.

In an ideal, $100 \%$ pure, silica glass having no impurity atoms only $Q^{4}$ units should exist. When dealing with real silica glasses, the several diffusivity data would be ideally compared, considering a single glass from the same batch (having exactly the same impurity content and consequently the same BO/NBO fraction), as we present in this paper for Puropsil A. In Fig. 2 the diffusivities and activation energies for silicon diffusion and for viscous flow for Puropsil A are indeed quite close.

It is not trivial to separately characterize the transport of oxygen in different chemical forms. However, recently Kajihara et $a l .{ }^{22}$ distinguished diffusion of molecular oxygen $\left(\mathrm{O}_{2}\right)$ from other oxygen species in silica glasses using photoluminescence. Their results were compared with oxygen permeation data of Norton ${ }^{23}$ and of Hetherington and Jack. ${ }^{24}$ The diffusivity values of molecular oxygen from these three sources are more than five orders of magnitude larger than those reported in our Fig. 2 for ionic oxygen. The slow diffusivities reported in Fig. 2 have been attributed to the hopping of oxygen ions belonging to the silica glass lattice. On the other hand, the structure of $\mathrm{SiO}_{2}$ glass is relatively sparse, allowing the incorporation of $\mathrm{O}_{2}$ without a significant interaction with the silica lattice; and thus oxygen molecules have much higher diffusivities than oxygen ions. The above discussion indicates that different oxygens have widely different mobilities, but we are not aware of measurements of nonbridging and bridging oxygen in the same glass.

To take into account the effective diffusion coefficients $D_{e f f}$ of all elements for multicomponent glass-forming melts, Schmelzer et al. ${ }^{11,12}$ proposed the following equation:

$$
D_{e f f}=\frac{1}{\sum_{i} \frac{\nu_{i}^{2}}{x_{i} D_{i}}},
$$

where $D_{i}$ is the partial diffusion coefficient of the different components in the system, $x_{i}$ is the molar fraction of each component in the melt, and the parameters $\nu_{i}$ are the coefficients describing the stoichiometric composition of the evolving crystalline phase. In our case $x_{\mathrm{Si}}=\frac{1}{2} x_{\mathrm{O}}$. Considering the experimental $D_{\mathrm{Si}}$ and $D_{\mathrm{O}}$, the calculated $D_{\text {eff }}$ was quite close to the silicon diffusivity obtained in Fig. 2.

The present results shed light in the dynamics of undercooled liquid silica in a wide range of undercoolings and diffusivities in a range of about eight orders of magnitude. Sophisticated theoretical models for silica ${ }^{19}$ intended to reach similar temperature and viscosity ranges, with encouraging results, but yet without success. It will thus be important to perform similar analyses from $T_{m}$ to $T_{g}$ for other glass-forming silicate liquids to ascertain whether or not the present findings can be generalized.

\section{CONCLUSIONS}

For silica glass, the normal growth model describes both the magnitude and temperature dependence of the crystal growth rates in a wide range of undercoolings, from the melting point to about $1.1 T_{g}$. The fitted jump distance is similar to the Si-O distance, confirming the consistency of the present calculations.

We deduced the effective diffusivities from crystal growth rates and from viscosity, and compared them with direct measurements for silicon and oxygen, i.e., in three distinct 
ways. These combined diffusivities cover eight orders of magnitude in a wide range of undercoolings. The effective diffusion coefficients calculated from crystal growth kinetics and viscosity closely agree with measurements of silicon self-diffusion coefficients, but are widely different from the diffusivity of oxygen. We assume that this difference arises from the fact that the measured diffusivities of oxygen refer to NBO, which move much faster than BO. The activation energies for viscous flow $(6.1 \pm 0.1 \mathrm{eV})$, silicon diffusion $(6.1 \pm 0.2 \mathrm{eV})$, and crystal growth $(5.7 \pm 0.2 \mathrm{eV})$ are quite similar. The single-bond strength between silicon and oxygen is about $4.8 \mathrm{eV}$, intermediate between the above values and the activation energy for oxygen diffusion $(1.1 \pm 0.2$ $\mathrm{eV}$ to $2.9 \pm 0.2 \mathrm{eV}$ ). Silicon diffusion thus controls the dynamics involved in both crystal growth and viscous flow in undercooled liquid silica.

As for silica glass, the Eyring equation is valid from the equilibrium liquid to about $1.1 T_{g}^{\circ}$, it is thus possible to esti- mate the whole crystal growth rate curve using independently measured physical parameters, such as the Si-O distance, the glass viscosity, and the thermodynamic driving force. Therefore, this study not only unveils the transport mechanism in this "simple" system, but also validates the use of viscosity to account for the transport term of the crystal growth expression in a wide temperature range.

\section{ACKNOWLEDGMENTS}

Financial support by the Brazilian agencies Capes, CNPq, and Fapesp are highly appreciated. The authors are greatly indebted to Dr. Eduardo B. Ferreira (Federal University of São Carlos, Brazil) for critically reviewing this manuscript and to George Reywer (Saint-Gobain Quartz PLC) for sending us useful information about the impurity content of Puropsil glass.
*Electronic address: pmlfn@iris.ufscar.br

†Electronic address: dedz@power.ufscar.br

${ }^{1}$ M. L. F. Nascimento, E. B. Ferreira, and E. D. Zanotto, J. Chem. Phys. 121, 8924 (2004).

${ }^{2}$ M. L. F. Nascimento and E. D. Zanotto, Phys. Chem. Glasses (to be published).

${ }^{3}$ G. Heterington, K. H. Jack, and J. C. Kennedy, Phys. Chem. Glasses 5, 130 (1964).

${ }^{4}$ F. E. Wagstaff, J. Am. Ceram. Soc. 51, 449 (1968).

${ }^{5}$ F. E. Wagstaff, J. Am. Ceram. Soc. 52, 650 (1969).

${ }^{6} \mathrm{~K}$. A. Jackson, in Growth and Perfection of Crystals, edited by R. H. Doremus, B. W. Roberts, and D. Turnbull (Wiley, New York, 1958).

${ }^{7}$ L. L. Burgner and M. C. Weinberg, Phys. Chem. Glasses 42, 184 (2001).

${ }^{8}$ L. W. Herron and C. G. Bergeron, Phys. Chem. Glasses 19, 89 (1978).

${ }^{9}$ X. P. Tang, U. Geyer, R. Busch, W. L. Johnson, and Y. Wu, Nature 402, 160 (1999).

${ }^{10}$ A. L. Greer, Nature 402, 132 (1999).

${ }^{11}$ J. W. P. Schmelzer, R. Müller, J. Möller, and I. S. Gutzow, J.
Non-Cryst. Solids 315, 144 (2003).

${ }^{12}$ J. W. P. Schmelzer, O. V. Potapov, V. M. Fokin, R. Müller, and S. Reinsch, J. Non-Cryst. Solids 333, 150 (2004).

${ }^{13}$ G. Brebec, R. Seguin, C. Sella, J. Bevenott, and J. C. Martin, Acta Metall. 28, 327 (1980).

${ }^{14}$ T. M. Clark, P. J. Grandinetti, P. Florian, and J. F. Stebbins, Phys. Rev. B 70, 064202 (2004).

${ }^{15}$ R. Haul and G. Dümbgen, Z. Elektrochem. 66, 636 (1962).

${ }^{16}$ J. D. Kalen, R. S. Boyce, and J. D. Cawley, J. Am. Ceram. Soc. 74, 203 (1991).

${ }^{17}$ H. A. Schaeffer, J. Non-Cryst. Solids 38\&39, 545 (1980).

${ }^{18}$ J. C. Mikkelsen, Appl. Phys. Lett. 45, 1187 (1984).

${ }^{19}$ K. Binder, J. Non-Cryst. Solids 274, 332 (2000).

${ }^{20}$ Saint-Gobain: http://www.quartz.saint-gobain.com

${ }^{21}$ Heraeus-Tenevo: http://www.heraeus-tenevo.de

${ }^{22}$ K. Kajihara, T. Miura, H. Kamioka, M. Hirano, L. Skuja, and H. Hosono, J. Ceram. Soc. Jpn. 112, 559 (2004).

${ }^{23}$ F. J. Norton, Nature 191, 701 (1961).

${ }^{24}$ G. Hetherington and K. H. Jack, Phys. Chem. Glasses 5, 147 (1964). 